\title{
Preferences for cervical cancer screening ser
attributes in rural China: a discrete choice experiment
}

This article was published in the following Dove Press journal: Patient Preference and Adherence

\author{
Shunping $\mathrm{Li}^{1,2}$ \\ Shimeng Liu ${ }^{1,2}$ \\ Julie Ratcliffe ${ }^{3}$ \\ Alastair Gray ${ }^{4}$ \\ Gang Chen ${ }^{5}$
}

\begin{abstract}
'School of Health Care Management, Shandong University, Jinan 250012 , People's Republic of China; ${ }^{2} \mathrm{NHC}$ Laboratory of Health Economics and Policy Research (Shandong University), Jinan, 2500 I2, People's Republic of China; ${ }^{3}$ Health Economics Group, College of Nursing and Health Sciences, Flinders University, Adelaide, South Australia 5042, Australia; ${ }^{4}$ Health Economics Research Centre, Nuffield Department of Population Health, University of Oxford, Oxford, UK; ${ }^{5}$ Flinders Centre for Innovation in Cancer, College of Medicine and Public Health, Flinders University, Adelaide, South Australia 5042, Australia
\end{abstract}

Correspondence: Gang Chen

Flinders Centre for Innovation in Cancer, Flinders University, Bedford Park,

Adelaide, South Australia 5042, Australia

$\mathrm{Tel}+6142581 \quad 1029$

Email gang.chen@flinders.edu.au
Objectives: Compared with other cancers, screening for cervical cancer is highly costeffective. However, due to limited awareness about cervical cancer and many other factors, women's attendance rate in rural China for cervical cancer screening remains low. This study aimed to determine women's preferences for cervical cancer screening, to help enhance screening uptake.

Methods: A discrete choice experiment (DCE) was conducted among a population-based random sample of 420 women (30-65 years old) in August 2015. Attributes included the percentage of cervical cancer-related death reduction, screening interval, screening location, screening pain, waiting time for screening results and out-of-pocket costs. Mixed logit models were used to analyze the relative importance of each screening attribute.

Results: When considering a screening program, the screening cost, location and the percentage of cervical cancer-related death reduction were of most concern to women. Among the presented attributes, the pain associated with the process of screening was of the least concern.

Conclusions: All six attributes in our study were found to have a large influence on the preference for cervical cancer screening, and significant preference heterogeneity existed among participants. The findings indicate that the maintenance of a free screening program is essential to increasing screening uptake in this vulnerable population.

Keywords: discrete choice experiment, cervical cancer, screening, preference, China

\section{Introduction}

Cervical cancer is the fourth most common female cancer globally and the leading cause of cancer death among women, accounting for almost $12 \%$ of all female cancers. ${ }^{1}$ Around $87 \%$ of the cervical cancer deaths occur in developing countries, where the number of new cases ranks cervical cancer second among malignancies in female patients. ${ }^{2,3}$

In China, there were an estimated 100,700 new cases of cervical cancer in 2013, ranking as the sixth most common incident cancer among all newly diagnosed cancers in females. ${ }^{4}$ Although the incidence of cervical cancer in China is low in comparison to that of western countries, the mortality rate remains high, especially in rural areas. ${ }^{5}$ A total of 29,526 women died of the disease in 2012 in China, accounting for $11 \%$ all cervical cancer deaths worldwide. ${ }^{2}$ Furthermore, forward projections indicate that the number of new cases will rise as high as 186,600 by $20500^{6}$ 
As a preventable and treatable disease, screening of precancerous lesions can reduce cervical cancer's incidence and mortality. Compared to other cancers, screening for cervical cancer is very cost-effective, because no other cancer offers as good a means for primary and secondary prevention as cervical cancer. ${ }^{7,8}$ However, in many developing countries, cervical cancer screening programs are unavailable or are poorly accessible. ${ }^{9}$ Although China has provided free cervical cancer screening programs in some rural areas for women aged 35 to 59 years since 2009 , a lack of awareness and knowledge and the absence of a nationwide organized cervical cancer screening program has resulted in many rural women remaining unaware of the benefits of screening and unwilling to undergo the procedure. Consequently, cervical cancer remains an important public health problem in mainland China. ${ }^{5}$

To improve patient-centered health care, it is important to investigate women's preferences for cervical cancer screening. Obtaining insights into these preferences will provide valuable information to clinicians and policy decision makers for improving screening uptake. ${ }^{10}$ The decision to participate or not in a screening program is preferably based on an individual decision-making process of weighting (or trading off) the test burden against the potential benefits of screening.

Worldwide, discrete choice experiment (DCE) has been extensively applied in health care research, in a wide range of contexts and addressing different policy and research issues. ${ }^{11}$ To date, there have been very limited studies using DCE to explore the preferences for cervical cancer screening. ${ }^{12-15}$ These studies found that cost, chance of being recalled, waiting time for test results, sensitivity of test, pain and the provider's gender were relatively more important when choosing a cervical cancer screening program by women. The objective of this study was to use a DCE, a quantitative methodology for investigating these trade-offs, to assess women's preferences for cervical cancer screening in rural China.

\section{Methods}

\section{Discrete choice experiment}

The methodology of DCEs is grounded in random utility theory, where a discrete choice is offered and participants choose the option with the highest utility among candidate options. ${ }^{16}$ The technique has been increasingly used in health economics to consider attribute importance in delivering health care, with consideration both to the aspect of the patient experience and health outcomes, as well as to tradeoffs between these and willingness to pay (WTP) for different attributes. ${ }^{11,17}$ In comparison with other quantitative methods (eg, a ranking task), a DCE task more closely resembles a real-world decision; in addition, the output from DCEs can facilitate future policy implementation (eg, the calculation of the uptake rate for hypothetical scenarios). ${ }^{18}$ In the context of this study, it is assumed that a cancer screening program can be described by a series of attributes and their corresponding levels. ${ }^{19}$ The DCE design and analysis was conducted following the International Society For Pharmacoeconomics and Outcomes Research (ISPOR) good practice principles outlined by Bridges et al. ${ }^{20}$

The salient features or characteristics (attributes) associated with the provision of cervical cancer screening and their associated levels were formulated from a literature review, ${ }^{12-15,21-24}$ coupled with a series of in-depth qualitative interviews with rural women $(\mathrm{N}=15)$ aged $30-65$ years old, and consultation with clinical experts in the field of cervical cancer screening in China. During the interview, women were asked to comment on a candidate list of cervical cancer screening attributes which were extracted from the literature review and to indicate any additional candidate attributes that were omitted from the literature review. Following this process and after consulting with the clinical experts, a total of six final attributes most relevant to cervical cancer screening in rural China were selected: the percentage of cervical cancer-related death reduction (with levels been determined by consulting clinicians as well as the levels of attribute "chance of dying from cervical cancer" adopted by Wordsworth et $\mathrm{al}^{15}$ ), screening interval, screening pain, screening location, waiting time for screening results and the out-of-pocket (OOP) costs (with levels been determined by the relevant local government document) (Table 1).

The combination of six attributes with three levels associated with each attribute resulted in $729\left(3^{6}\right)$ possible cervical cancer screening scenarios and a total of 265,356 possible pairwise choices $((729 \times 728) / 2)$. A sequential orthogonal factorial design was adopted to generate a more manageable 27 choice scenarios (which were further blocked into three versions containing 9 choice sets each) using the Ngene version 1.1.2 DCE design software (Choice-Metrics, Sydney, Australia). Within each version, a single choice set was duplicated to examine the internal consistency of participants.

Each discrete choice set consisted of two cervical cancer screening alternatives. Participants were first asked to 
Table I DCE attributes and levels

\begin{tabular}{|c|c|}
\hline Attribute I & $\begin{array}{l}\text { The percentage of cervical cancer-related } \\
\text { death reduction }\end{array}$ \\
\hline Level I & Reduced $20 \%$ \\
\hline Level 2 & Reduced $50 \%$ \\
\hline Level 3 & Reduced $80 \%$ \\
\hline Attribute 2 & Screening interval \\
\hline Level I & Every three years \\
\hline Level 2 & Every two years \\
\hline Level 3 & Every year \\
\hline Attribute 3 & Screening location \\
\hline Level I & County \\
\hline Level 2 & Town \\
\hline Level 3 & Village \\
\hline Attribute 4 & Screening pain \\
\hline Level I & Moderate \\
\hline Level 2 & Mild \\
\hline Level 3 & None \\
\hline Attribute 5 & Waiting time for screening results \\
\hline Level I & Three months to half year \\
\hline Level 2 & Two weeks to three months \\
\hline Level 3 & Within two weeks \\
\hline Attribute 6 & Out-of-pocket costs \\
\hline Level I & $300 \mathrm{CNY}$ \\
\hline Level 2 & $50 \mathrm{CNY}$ \\
\hline Level 3 & $0 \mathrm{CNY}$ \\
\hline
\end{tabular}

Notes: The average annual exchange rate between U\$ and CNY in 2015 was: US $\$ I=$ CNY 6.227 .

consider two alternatives in a choice set and to choose the alternative that they preferred. Secondly, participants were asked a follow-up question as to whether in real life they would be willing to participate in their preferred scenario (see Table 2 for an example choice set, and another example in Chinese in Figure S1). The above two questions were combined together for analysis to facilitate an "opt out" option. $^{25}$

\section{Participants}

A stratified random sampling framework was utilized. In the first step, four counties (Rencheng County, Qufu County, Sishui County and Yutai County) out of a total of 11 counties in Jining Prefecture were randomly selected. Next, two townships were randomly selected within each county and then two villages were randomly selected from within each sampled township. Finally, a minimum of 100 women aged 30 to 65 years for each county were randomly selected from potential candidate participants identified by each village committee.
Table 2 An example discrete choice task. Please consider the following two cervical cancer screening scenarios and let us know your preference by ticking the corresponding box. Will you actually participate in the screening program you chose if it was offered to you?

\begin{tabular}{|c|c|c|}
\hline Attribute & $\begin{array}{l}\text { Screening } \\
\text { scenario I }\end{array}$ & $\begin{array}{l}\text { Screening } \\
\text { scenario } 2\end{array}$ \\
\hline $\begin{array}{l}\text { The percentage of cervical cancer- } \\
\text { related death reduction }\end{array}$ & Reduced $80 \%$ & Reduced $20 \%$ \\
\hline Screening interval & $\begin{array}{l}\text { Every three } \\
\text { years }\end{array}$ & Every year \\
\hline Screening location & County & Village \\
\hline Screening pain & None & Mild \\
\hline Waiting time for results & $\begin{array}{l}\text { Within } 2 \\
\text { weeks }\end{array}$ & $\begin{array}{l}2 \text { weeks-3 } \\
\text { months }\end{array}$ \\
\hline Out-of-pocket costs & $300 \mathrm{CNY}$ & $0 \mathrm{CNY}$ \\
\hline Your preference? & $\square$ & $\square$ \\
\hline $\begin{array}{l}\text { Will you actually participate in the } \\
\text { screening program you chose if it } \\
\text { was offered to you? }\end{array}$ & $\square$ Yes & $\square$ No \\
\hline
\end{tabular}

Women who had previously had a hysterectomy or who indicated no prior sexual experience were excluded from participation. ${ }^{26}$

Women in rural China are often less well-educated relative to their urban counterparts. The DCE questionnaire was therefore administered as a one-to-one face-to-face interview to assist the participant in understanding and completing the DCE task, thereby ensuring the quality of the investigation. Participants received an insulated cup (35 Chinese Yuan; the average annual exchange rate between US\$ and CNY in 2015 was US $\$ 1=\mathrm{CNY} 6.227$ ) as a gift following survey completion. Five researchers from Shandong University who were able to speak in the relevant local dialect were trained to administer the DCE questionnaire via a face-to-face interview. The survey contains four sections. Section A contained a series of questions regarding participants' socio-demographic characteristics; Section B included cervical cancer knowledge; Section $\mathrm{C}$ assessed participants' attitudes towards cervical cancer and its screening; Section D contained the DCE task. Results regarding participants' cervical cancer knowledge and attitudes have been published in a separate paper. ${ }^{26}$ The full questionnaire was piloted among 10 rural women in Sishui County, aiming to examine the intelligibility, acceptability, and validity of the questionnaire. The survey data was collected in August 2015. The process of administering the questionnaire took about 30 to 40 mins on average and all completed questionnaires were returned directly to the investigators. 


\section{Data analysis}

Taking into account potential preference heterogeneity, a mixed logit model was used to analyze the DCE data. ${ }^{27,28}$ The utility function can be specified as:

$$
\mathrm{U}_{\mathrm{ijt}}=\mathrm{X}_{\mathrm{ijt}}{ }^{\prime} \beta_{\mathrm{i}}+\varepsilon_{\mathrm{ijt}}
$$

where $U_{i j t}$ is the utility individual $\mathrm{i}$ derives from choosing alternative $\mathrm{j}$ in choice scenario $\mathrm{t}, \mathrm{X}$ is a vector of observed attributes (ie, the cervical cancer screening characteristics and corresponding levels), $\beta$ is a vector of coefficients reflecting the desirability of the attributes, and $\varepsilon_{\mathrm{ijt}}$ is an error term. Although most previous studies specify the coefficient for monetary attribute in choice models to be fixed, it is often unrealistic to assume that all participants have the same preferences regarding the costs of a cervical cancer screening program. ${ }^{29}$ In our study, all attributes were specified as having a random component. In addition, all attribute variables were coded as dummy variables except for cost which was specified as a continuous variable.

To reveal the trade-offs that participants were willing to make between screening attributes, the WTP for marginal improvements in the attributes (which were calculated by dividing the estimated coefficients for the remaining attributes by the estimated coefficient for the cost attribute) and associated confidence intervals were estimated. ${ }^{30}$ The WTP estimates will facilitate policy makers in understanding how much out-of-pocket cost an individual would be willing to incur for improvements in other attributes of a screening program. Finally, by using the estimated coefficients, the uptake rates of a cervical cancer screening program were calculated. ${ }^{31}$ Such information would be useful for future policy implementation in rural China. All statistical analyses were conducted in Stata version 12.1 (StataCorp LP, College Station, Texas, USA).

\section{Results}

\section{Participants}

A total of 420 women consented to participate in this study. Among these, 405 (96\%) successfully completed the survey, 57 (14\%) participants failed the consistency test in the duplicated DCE task, and there were no statistically significant differences in demographic characteristics between those who failed versus who passed the test (see Table 3).

Table 3 Demographic characteristics of participants

\begin{tabular}{|c|c|c|c|c|c|c|c|}
\hline Characteristics of participants & \multicolumn{2}{|c|}{$\begin{array}{l}\text { Full sample } \\
\mathbf{N}=405\end{array}$} & \multicolumn{2}{|c|}{$\begin{array}{l}\text { Analysis sample (who } \\
\text { passed the consistency } \\
\text { test) } N=348\end{array}$} & \multicolumn{2}{|c|}{$\begin{array}{l}\text { Excluded sample (who } \\
\text { failed the consistency } \\
\text { test) } N=57\end{array}$} & $\chi 2$ (P-value) \\
\hline Age (year), N (\%) & & & & & & & $0.940(0.6)$ \\
\hline Mean \pm SD & 49.2 & 8.30 & 49.1 & 8.33 & 50.1 & 8.10 & \\
\hline $30-44$ & 110 & $27.2 \%$ & 97 & $27.9 \%$ & 13 & $22.8 \%$ & \\
\hline $45-54$ & 185 & $45.6 \%$ & 159 & $45.7 \%$ & 26 & $45.6 \%$ & \\
\hline $55-65$ & 110 & $27.2 \%$ & 92 & $26.4 \%$ & 18 & $31.6 \%$ & \\
\hline Marital status, N (\%) & & & & & & & $2.170(0.3)$ \\
\hline Married & 390 & $96.3 \%$ & 336 & $96.6 \%$ & 54 & $94.7 \%$ & \\
\hline Divorced or widowed & 15 & $3.7 \%$ & 12 & $3.4 \%$ & 3 & $5.3 \%$ & \\
\hline Education level, N (\%) & & & & & & & $4.892(0.3)$ \\
\hline Did not complete primary school & 111 & $27.4 \%$ & 93 & $26.7 \%$ & 18 & $31.6 \%$ & \\
\hline Completed Primary school & 124 & $30.6 \%$ & 102 & $29.3 \%$ & 22 & $38.6 \%$ & \\
\hline Completed Middle school & 134 & $33.1 \%$ & 120 & $34.5 \%$ & 14 & $24.6 \%$ & \\
\hline Completed High school or above & 36 & $8.9 \%$ & 33 & $9.5 \%$ & 3 & $5.3 \%$ & \\
\hline Family income (CNY), N (\%) & & & & & & & $0.966(0.8)$ \\
\hline$<10,000$ & 104 & $25.7 \%$ & 88 & $25.3 \%$ & 16 & $28.1 \%$ & \\
\hline $10,000-20,000$ & 104 & $25.7 \%$ & 89 & $25.6 \%$ & 15 & $26.3 \%$ & \\
\hline $20,000-30,000$ & 91 & $22.4 \%$ & 81 & $23.3 \%$ & 10 & $17.5 \%$ & \\
\hline$>30,000$ & 106 & $26.2 \%$ & 90 & $25.9 \%$ & 16 & $28.1 \%$ & \\
\hline
\end{tabular}


Women who passed the consistency test had a mean (standard deviation, SD) age of 49.1 (8.3) years, the vast majority (96.6\%) were married, and around half (50.9\%) had an annual family income lower than 20,000 CNY.

\section{DCE results}

The DCE results based on the analysis sample are reported in Table 4 and Table S1. It can be seen that the main findings are similar regardless of whether participants who failed the consistency test are included or excluded. As such, the following discussions are based on those who passed the consistency test only. First, the signs on all attributes were as expected and were significantly different from zero with the exception of the mild pain level. Second, unobservable preference heterogeneity (as reflected in the estimated standard deviations of the mean coefficients) existed for four out of six attributes, the two attributes having homogeneous preference being the percentage of cervical cancer-related death reduction and screening pain. Third, on average rural women in this study indicated a positive preference to participate in cervical cancer screening (as indicated by the significantly negative coefficient attached to the alternative-specific constant, "No screening").

The WTP estimates for the analysis sample $(n=348)$ are also presented in Table 4. Compared to the reference levels for each attribute, screening location and the percentage risk reduction in cervical cancer-related deaths had the largest impact on the preferences for screening. For example, compared to having screening in the county, participants were willing to pay $52 \mathrm{CNY}$ and $110 \mathrm{CNY}$ to participate in a cervical cancer screening program located in town and village, respectively. In comparison to a waiting time of between 3 and 6 months, participants were willing to pay $44 \mathrm{CNY}$ and $61 \mathrm{CNY}$ to reduce waiting times to between 2 weeks and 3 months, and to less than 2 weeks, respectively.

Selected subgroup analyses results are presented in $\underline{\text { Tables S2 }}$ and S3. As can be seen, for the majority of subgroups all six attributes remained statistically significant in influencing preferences, with the exception of two subgroups (higher educated and no screening experience) in which the screening pain attribute became nonsignificant. Focusing on the WTP estimates, it can be seen that that those participants who were highly educated and/or with higher family incomes, were willing to pay more on average for a higher percentage of cervical cancer-related death reduction, lower screening intervals and shorter waiting time for screening results. Those who had been screened previously were willing to pay more for lower screening intervals and shorter waiting time for screening results. Overall the subgroup analyses also suggest the existence of observable preference heterogeneity among participants.

Finally, the calculated uptake rates based upon the full sample are shown in Figure 1. A reduction in the

Table 4 Main effects model for DCE $(n=348)$

\begin{tabular}{|c|c|c|c|c|c|}
\hline Attribute levels & Mean (SE) & SD (SE) & WTP (CNY) & \multicolumn{2}{|c|}{ 95\% Confidence interval } \\
\hline No screening & $-4.309 * *(0.599)$ & $5.532 * *(0.526)$ & & & \\
\hline Reduced $50 \%$ & $0.877^{* *}(0.113)$ & $0.055(0.163)$ & 66.829 & 49.333 & 85.489 \\
\hline Reduced $80 \%$ & $1.404 * *(0.127)$ & $0.503(0.274)$ & 106.942 & 87.483 & 129.774 \\
\hline Every 2 years & $0.992 * *(0.122)$ & $0.299(0.305)$ & 75.606 & 57.220 & 96.445 \\
\hline Every year & $1.260 * *(0.131)$ & $1.174 * *(0.168)$ & 96.000 & 75.892 & 119.296 \\
\hline Town & $0.678 * *(0.128)$ & $0.963 * *(0.193)$ & 51.680 & 32.708 & 72.570 \\
\hline Village & $1.448 * *(0.124)$ & $0.684^{* *}(0.191)$ & 110.270 & 91.514 & 131.890 \\
\hline Mild pain & $-0.219(0.114)$ & $0.074(0.193)$ & -16.667 & -34.738 & 0.147 \\
\hline No pain & $0.270 * *(0.094)$ & $0.119(0.260)$ & 20.582 & 6.628 & 34.994 \\
\hline 2 weeks -3 months & $0.58 I * *(0.118)$ & $0.131(0.232)$ & 44.256 & 26.627 & 63.301 \\
\hline$<2$ weeks & $0.802 * *(0.118)$ & $0.799 * *(0.161)$ & 61.103 & 43.738 & 80.772 \\
\hline Cost & $-0.013^{* *}(0.001)$ & $0.009 * *(0.00 \mathrm{I})$ & & & \\
\hline Log likelihood & \multirow{3}{*}{\multicolumn{2}{|c|}{$\begin{array}{l}-1899.8619 \\
348 \\
9,396\end{array}$}} & & & \\
\hline Participants & & & & & \\
\hline Observations & & & & & \\
\hline
\end{tabular}

Notes: Mixed logit estimates reported. $* P<0.05 ; * * P<0.01$. Dummy coding used except for the cost variable.

Abbreviations: SD, Standard Deviation estimates reflect preference heterogeneity in the participants; SE, Standard Error. 


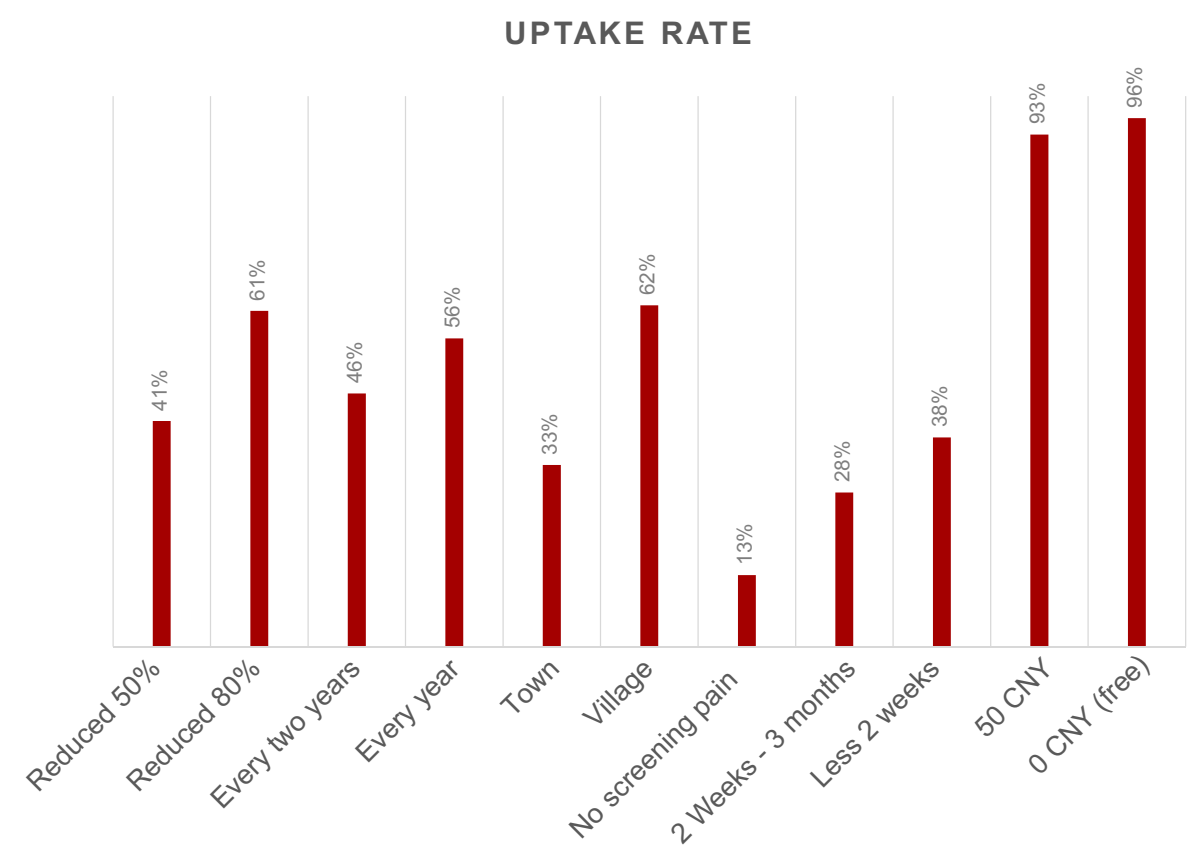

Figure I Simulated probability for cervical cancer screening under various potential policy scenarios. Baseline cervical cancer screening program: the percentage of cervical cancer-related death reduction " $20 \%$ "; screening location "county"; screening interval "every three years"; moderate screening pain; waiting time for screening results " 3 months - 6 months"; out-of-pocket cost " 300 CNY".

out-of-pocket costs associated with screening from 300 CNY to 50 and $0 \mathrm{CNY}$ had the largest effect on preference of women to choose to participate in a cervical cancer screening program, increasing the probability of uptake by $93 \%$ and $96 \%$, respectively. In contrast, compared with a moderate degree of pain associated with the screening process, the absence of pain enhances the probability of uptake by only $13 \%$ overall.

\section{Discussion}

To the best of our knowledge, this is the first study to utilize DCE methodology to elicit women's preferences for cervical screening attributes in China. All six attributes considered in this study were found to be statistically significant in influencing individual preferences to participate (or not) in a cervical cancer screening program.

The percentage of cervical cancer-related death reduction has an important positive influence on preferences for cervical cancer screening. Our finding that women attach much importance to cervical cancer mortality reduction is consistent with the results of a previous study conducted in Scotland. ${ }^{15}$ Furthermore, the finding that participants were willing to pay more on average for screening programs associated with higher percentage of cervical cancer-related death reduction demonstrates that they trade benefits and costs of a screening test. When comparing the WTP estimates between different subgroups, women with higher education and income levels were prepared to pay more for the percentage of cervical cancer-related death reduction relative to those with lower education and income levels. This finding may be related to the ability to pay or the fact that women with higher education and income levels are more likely to pay more attention to their health and have more opportunities to obtain relevant information and thereby increase their cervical cancer screening knowledge. ${ }^{26}$

In relation to screening intervals, our findings reinforce those of previous studies which have identified that participants tend to prefer a shorter screening interval over a longer screening interval. There is evidence to suggest that women feel that longer waiting times expose them to a higher risk of contracting cervical cancer, and are therefore associated with increased worry and anxiety. ${ }^{15,32}$

With regards to OOP costs, compared with a screening program that require women to pay 300 CNY to access, providing a free cost screening program will increase the uptake rate by $96 \%$. In comparison, a study conducted in the UK by Wordsworth et $\mathrm{al}^{15}$ found that a unit change in the cost of screening was the least important attribute. The difference may be due to relative affluence of the UK cohort relative to this study and therefore their increased capacity/ability to 
pay relative to rural Chinese women, or to difficulties in accepting the possibility of out-of-pocket costs in a predominantly free at point of use health system. In addition, several previous studies including those by Murray and McMillan ${ }^{33}$ in Northern Ireland (on breast cancer screening) and Doyle ${ }^{34}$ in the UK found the fear of the associated pain to be one of the most important reasons for declining screening. These findings contrast with the finding from our study that the pain associated with the screening process was considered to be relatively unimportant in influencing uptake.

All of the participants in our study came from rural areas, and for the majority, their annual family income was relatively low (less than 30,000 CNY). In addition, cervical cancer screening is currently provided free of charge in some rural areas. Hence, our finding that participants strongly preferred not to have to pay any out-of-pocket costs for screening is unsurprising. In a previous study conducted by our team we found that although Chinese governments currently provide free cervical cancer screening for target populations in pilot counties, if women were asked to contribute towards the cost of providing these screening services in the future, it will become an additional barrier preventing uptake for many rural Chinese women. $^{26}$ Consequently maintaining a cervical cancer screening program that is freely accessible is crucial for increasing uptake amongst women in rural China.

A previous study conducted by Fort et $\mathrm{al}^{21}$ in rural locations in Malawi indicated that village participants were particularly frustrated with the waiting times to receive cervical cancer screening results from the District Hospital, and longer waiting times tended to negatively influence uptake rates. Our study found similar results, in that reducing the waiting time to receive results from 6 months to less than 2 weeks enhanced the probability of uptake by $38.1 \%$ overall. In relation to the subgroup analyses, we found that those with higher education and family income levels were willing to pay about 3 times more on average to receive their results within 2 weeks than those with lower education and family income levels. Women with higher education and income levels were more likely to be working full time and have higher capability to pay due to higher disposable income levels. In addition, waiting excessively long time periods for the results may be associated with a higher opportunity cost for them.

For screening location, the participants prefer the location "village" and there was no significant difference between the subgroups. Hence, this finding cannot be explained by knowledge levels, family income and previous cervical cancer screening history. The higher cost and inconvenience associated with attending cervical cancer screening far away from home for women could be a potential explanation for this finding. The majority (74\%) of participants in our study were less than 55 years old and they were more likely to be working full time or taking care of younger children at home. ${ }^{26}$ A DCE study conducted in the Netherlands to investigate preferences for colorectal cancer screening also reported similar findings in that participants preferred the location "home" rather than hospital. ${ }^{35}$ Our findings indicate that the provision of cervical cancer screening programs in primary health care institutions located close to women's homes has the potential to enhance the cervical cancer screening uptake in rural areas of China.

This study has some limitations. First, as with all DCE results it is based on 'stated preferences', rather than on 'revealed preferences'. To verify the credibility of this study's results, further research would ideally compare the stated preferences of women with their actual behavior in a cervical cancer screening program. Second, only rural women from four counties were included in this research and hence the findings are limited in their generalizability. Differences may exist between cervical cancer screening preferences and the likelihood of uptake for women living in rural China relative to those living in urban areas. Further research should be conducted to explore the potential for differences in women's preferences according to geographical location. Thirdly, there may be some concerns about the appropriateness of the attribute "the percentage of cervical cancer-related death reduction" since the range of its level ( $20 \%$ to $80 \%$ ) seems too large to be realistic. It should be noted that this does not refer to the reduction on the absolute mortality rate, but a percentage change. For example, in Wordsworth et al, the implied largest percentage change (reduction) on the "chance of dying from cervical cancer" was $(0.4 \%-2 \%) / 2 \%=-80 \%$. We opted to present this attribute as percentage change rather than the absolute mortality since it is easier for our respondents to understand the magnitude of the vaccination benefit. Finally, since the participants in this study were from rural areas with relatively low education levels on average, there could be some concern about the extent to which the participants fully understood the DCE task. However, in the field, the DCE survey was conducted via a one-to-one face-to-face interview by trained researchers who spoke the local dialect to maximize the probability that participants would fully 
understand the DCE task. In addition, there was no significant association between education and passing the consistency check. Furthermore, following the strategy adopted by Milte et al, $^{36}$ we have empirically investigated this potential issue by estimating a generalized multinomial logit model within which the lowest education level was specified to impact on scale heterogeneity. The statistically nonsignificant coefficient attached to the estimated dummy variable reflecting the lowest education level further indicates that those in the lowest education level did not reveal less consistent preferences relative to those with higher education levels.

\section{Conclusion}

Cervical cancer is one of the most preventable cancers and is curable at early stages. Although a nationwide screening program, publicly funded and free at the point of access, has been launched for rural women in China, the universal screening rate has to date not attained high uptake with around one-third of candidate women never participating in screening. This study used DCE methodology to investigate six key factors influential in determining women's preferences for participation in cervical cancer screening programs in rural China. All six attributes were found to be significantly influential in affecting women's preferences for cervical cancer screening. In addition, there exists a certain degree of both observable and unobservable preference heterogeneity among participants. The findings from this study will help policy makers further improve cervical cancer screening uptake rates in rural China and have the potential to influence cervical cancer screening uptake rates in other developing countries with similar characteristics.

\section{Details of ethics approval}

Verbal informed consent was obtained from all participants prior to the survey. This study (including this consent process) was approved by the Medical Ethics Committee of Medical School, Shandong University (LL-201401048), and conforms to the ethics guidelines of the Declaration of Helsinki.

\section{Acknowledgments}

We thank Tongtong Liu, Luhong Sun for their assistance at the stage of data collection. We are grateful to all the participants for their time and effort. Responsibility for any remaining errors lies solely with the authors. This study was supported by China Medical Board Open Competition Grant (Grant number CMB14-195). An early version of this study has been presented at the 2016 International Society for Pharmacoeconomics and Outcomes Research (ISPOR) 7th Asia Pacific Conference and the abstract has been published online (https://doi.org/10.1016/j.jval.2016. $08.251)$

\section{Author contributions}

All authors contributed to data analysis, drafting and revising the article, gave final approval of the version to be published, and agree to be accountable for all aspects of the work.

\section{Disclosure}

The authors report no conflicts of interest in this work.

\section{References}

1. Ferlay J, Soerjomataram I, Dikshit R, et al. Cancer incidence and mortality worldwide: sources, methods and major patterns in GLOBOCAN 2012. Int $J$ Cancer. 2015;136(5):E359-386. doi: $10.1002 / \mathrm{ijc} .29210$

2. IARC. GLOBOCAN 2012: estimated cancer incidence mortality and prevalence worldwide in 2012; 2012. http://globocan.iarc.fr/Pages/ fact_sheets_cancer.aspx?cancer=cervix. Accessed April 8, 2018.

3. Song B, Ding C, Chen W, Sun H, Zhang M, Chen W. Incidence and mortality of cervical cancer in China, 2013. Chin J Cancer Res. 2017;29(6):471-476. doi:10.21147/j.issn.1000-9604.2017.06.01

4. Chen WQ, Zheng RS, Zhang SW, et al. Cancer incidence and mortality in China, 2013. Cancer Lett. 2017;401:63-71. doi:10.1016/j. canlet.2017.04.024

5. Jing L, Leni K, Youlin Q. Review of the cervical cancer disease burden in mainland China. Asian Pac $J$ Cancer Prev. 2011;12:1149-1153

6. Shi JF, Canfell K, Lew JB, Qiao YL. The burden of cervical cancer in China: synthesis of the evidence. Int J Cancer. 2012;130(3):641-652. doi:10.1002/ijc. 26042

7. Hakama M, Miller AB, Day NE. Screening for cancer of the uterine cervix: from the IARC Working Group on Cervical Cancer Screening and the UICC Project Group on the Evaluation of Screening Programmes for Cancer. Lyon: International Agency for Research on Cancer. 1986.

8. Petry KU. HPV and cervical cancer. Scand J Clin Lab Invest Suppl. 2014;244:59-62. doi:10.3109/00365513.2014.936683

9. Jia Y, Li S, Yang R, et al. Knowledge about cervical cancer and barriers of screening program among women in Wufeng County, a high-incidence region of cervical cancer in China. PLoS One. 2013;8 (7):e67005. doi:10.1371/journal.pone.0067005

10. de Bekker-Grob EW, Rose JM, Donkers B, Essink-Bot ML, Bangma CH, Steyerberg EW. Men's preferences for prostate cancer screening: a discrete choice experiment. Br J Cancer. 2013;108 (3):533-541. doi:10.1038/bjc.2013.5

11. de Bekker-Grob EW, Ryan M, Gerard K. Discrete choice experiments in health economics: a review of the literature. Health Econ. 2012;21 (2):145-172. doi:10.1002/hec.1697

12. Basen-Engquist K, Fouladi RT, Cantor SB, et al. Patient assessment of tests to detect cervical cancer. Int J Technol Assess Health Care. 2007;23(2):240-247. doi:10.1017/S0266462307070171

13. Fiebig DG, Haas M, Hossain I, Street DJ, Viney R. Decisions about Pap tests: what influences women and providers? Soc Sci Med. 2009;68(10):1766-1774. doi:10.1016/j.socscimed.2009.03.002 
14. Wittenberg E, Bharel M, Saada A, Santiago E, Bridges JF, Weinreb L. Measuring the preferences of homeless women for cervical cancer screening interventions: development of a best-worst scaling survey. Patient. 2015;8(5):455-467. doi:10.1007/s40271-014-0110-Z

15. Wordsworth S, Ryan M, Skatun D, Waugh N. Women's preferences for cervical cancer screening: a study using a discrete choice experiment. Int J Technol Assess Health Care. 2006;22(3):344-350.

16. Lancsar E, Louviere J. Conducting discrete choice experiments to inform healthcare decision making: a user's guide. Pharmacoeconomics. 2008;26 (8):661-677. doi:10.2165/00019053-200826080-00004

17. Hemming K. Discrete choice experiments: helping to understand how patients make decisions and promoting non-paternalistic care. Bjog. 2015;122(6):881. doi:10.1111/1471-0528.12965

18. Ryan M, Gerard K, Amaya-Amaya M. Using Discrete Choice Experiments to Value Health and Health Care. Dordrecht: Springer; 2008.

19. Ryan M. Discrete choice experiments in health care. Bmj. 2004;328 (7436):360-361. doi:10.1136/bmj.328.7436.360

20. Bridges JFP, Hauber AB, Marshall D, et al. Conjoint analysis applications in health-a checklist: a report of the ISPOR good research practices for conjoint analysis task force. Value Health. 2011;14 (4):403-413. doi:10.1016/j.jval.2010.11.013

21. Fort VK, Makin MS, Siegler AJ, Ault K, Rochat R. Barriers to cervical cancer screening in Mulanje, Malawi: a qualitative study. Patient Prefer Adherence. 2011;5:125-131. doi:10.2147/PPA.S17317

22. Moyer VA. Screening for cervical cancer: U.S. preventive services task force recommendation statement. Ann of Intern Med. 2012;156 (12):880-891. doi:10.7326/0003-4819-156-12-201206190-00424

23. Watts L, Joseph N, Velazquez A, et al. Understanding barriers to cervical cancer screening among Hispanic women. Am J Obstet Gynecol. 2009;201(2):199e191-198. doi:10.1016/j.ajog.2009.05.014

24. Abdullahi A, Copping J, Kessel A, Luck M, Bonell C. Cervical screening: perceptions and barriers to uptake among Somali women in Camden Public Health. 2009;123(10):680-685. doi:10.1016/j.puhe.2009.09.011

25. Marshall HS, Chen G, Clarke M, Ratcliffe J. Adolescent, parent and societal preferences and willingness to pay for meningococcal B vaccine: a discrete choice experiment. Vaccine. 2016;34 (5):671-677. doi:10.1016/j.vaccine.2015.11.075

26. Liu T, Li S, Ratcliffe J, Chen G. Assessing knowledge and attitudes towards cervical cancer screening among rural women in Eastern China. Int $J$ Environ Res Public Health. 2017;14(9):967. doi:10.3390/ijerph14090967
27. Kruk ME, Johnson JC, Gyakobo M, et al. Rural practice preferences among medical students in Ghana: a discrete choice experiment. Bull World Health Organ. 2010;88(5):333-341. doi:10.2471/ BLT.09.072892

28. McFadden D, Train K. Mixed MNL models for discrete response. $J$ Appl Econ. 2000;15(5):447-470. doi:10.1002/(ISSN)1099-1255

29. Hole AR, Kolstad JR. Mixed logit estimation of willingness to pay distributions: a comparison of models in preference and WTP space using data from a health-related choice experiment. Empir Econ. 2012;42(2):445-469. doi:10.1007/s00181-011-0500-1

30. Hole AR. A comparison of approaches to estimating confidence intervals for willingness to pay measures. Health Econ. 2007;16 (8):827-840. doi:10.1002/hec.1197

31. World Health Organization, CapacityPlus-USAID, Bank TW. How to Conduct A Discrete Choice Experiment for Health Workforce Recruitment and Retention in Remote and Rural Areas: A User Guide with Case Studies. Geneva: WHO; 2012.

32. Hawkins NA, Benard VB, Greek A, Roland KB, Manninen D, Saraiya M. Patient knowledge and beliefs as barriers to extending cervical cancer screening intervals in federally qualified health centers. Prev Med. 2013;57(5):641-645. doi:10.1016/j. ypmed.2013.08.021

33. Murray M, McMillan C. Social and behavioural predictors of women's cancer screening practices in Northern Ireland. J Public Health Med. 1993;15(2):147-153.

34. Doyle Y. A survey of the cervical screening service in a London district, including reasons for non-attendance, ethnic responses and views on the quality of the service. Soc Sci Med. 1991;32 (8):953-957.

35. Dam L, Bekker-Grob D. What determines individuals' preferences for colorectal cancer screening programmes? A discrete choice experiment. Eur J Cancer. 2010;46(1):150-159. doi:10.1016/j. ejca.2009.07.014

36. Milte R, Ratcliffe J, Chen G, Lancsar E, Miller M, Crotty M. Cognitive overload? An exploration of the potential impact of cognitive functioning in discrete choice experiments with older people in health care. Value Health. 2014;17(5):655-659. doi:10.1016/j. jval.2014.05.005
Patient Preference and Adherence

\section{Publish your work in this journal}

Patient Preference and Adherence is an international, peer-reviewed, open access journal that focusing on the growing importance of patient preference and adherence throughout the therapeutic continuum. Patient satisfaction, acceptability, quality of life, compliance, persistence and their role in developing new therapeutic modalities and compounds to optimize clinical outcomes for existing disease states are major areas of interest for the journal. This journal has been accepted for indexing on PubMed Central. The manuscript management system is completely online and includes a very quick and fair peer-review system, which is all easy to use. Visit http:// www.dovepress.com/testimonials.php to read real quotes from published authors. 